\title{
AUTUMN BOOKS
}

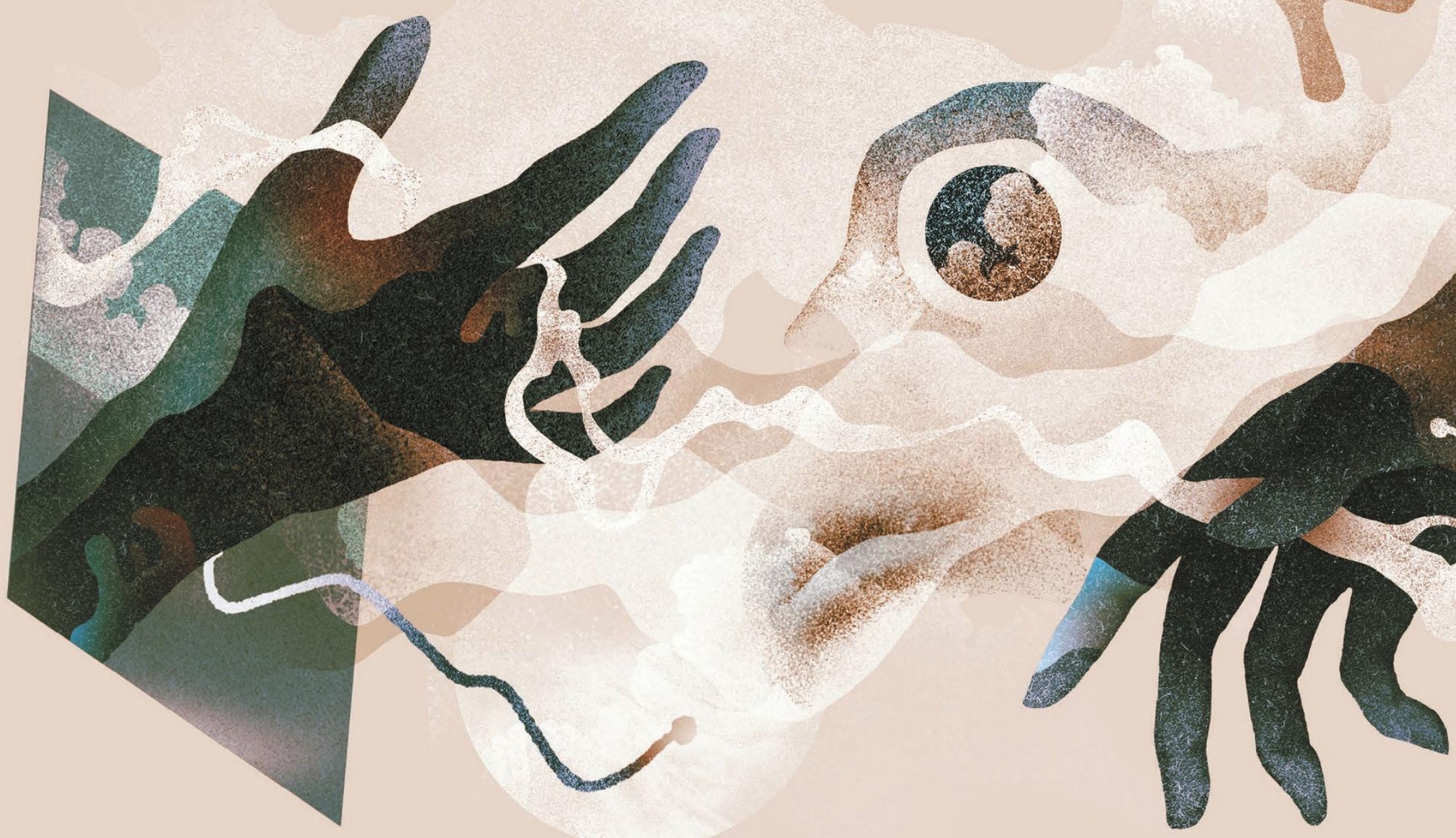

Robert P. Crease weighs up a theoretical-physics study that cracks open a strange vista.

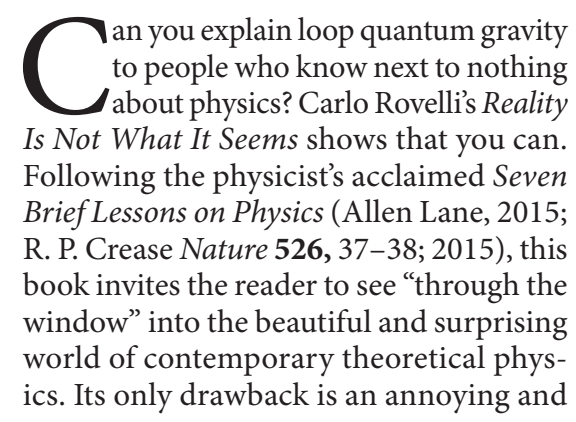

unnecessary presumption, announced by the title, that suggests that the view out of the window is into reality itself.

In most respects, this book is a model of popular science writing. The first half provides a select series of vistas on early thinkers and their ideas, to prepare the ground for the adventure of the second half. Rovelli evokes classical Greek philosophers Aristotle and Democritus to familiarize us with the question of whether, at base, the natural world is continuous and smoothly varying, like a beach seen from afar, or grainy, like a beach seen close up - that is, with no arbitrarily small amount of matter. Isaac Newton's seventeenth-century vista shows us reality as an infinite space in which time passes and particles push each other about with mathematically describable forces, such as his laws of motion and universal gravitation. Michael Faraday and James Clerk Maxwell contribute two new things: 
